\title{
INTEGRATED PRACTICE IN CONSTRUCTION
}

\author{
Sunil M K \\ Head, Architecture, Engineering \& Construction (AEC) division \\ Autodesk Asia Pacific (Emerging)
}

Integrated Practice is a large issue being discussed by architects and construction managers today: Changing the relationships between the activities of design, construction and facilities management. And at the center of that discussion is this idea of Building Information Modeling.

Building Information Modeling is a strategy, a tool using technology, to represent buildings as digital simulations rather than using technologies to make traditional CAD drafting drawings. And that idea really addresses this concept of Integrated Practice in a fundamental way. It's a platform to understand the Lifecycle of Buildings, the relationship between the players and the project, methodologies for collaboration, and giving the ability to create profound design information as part of the design process.

BIM is key to be able to do early analysis and be able to optimize design. The same data would help all the stake holders to make better decisions as it help construction superintendents, schedulers, modelers and subcontractors all work together to develop a strategy before any equipment shows up on the jobsite. Ideally, when the job begins, the stakeholders understand the project's sequencing and staging, thereby reducing project delivery times, risk, costs and potential lawsuits.

BIM also supports Sustainable design. The technology is key to some of the answers we need in terms how does day lighting, glare, energy consumption, occupancy comforts affected through the changes in design. We will better understand how the building fits together and performs.

Technology can help to understand buildings and infrastructure before its built and Autodesk have invested time and resources to bring these technology to these stake holders. 